Perspective

\title{
Fabricating High-Quality 3D-Printed Alloys for Dental Applications
}

\author{
Min-Ho Hong ${ }^{1}$ (D), Bong Ki Min ${ }^{2}$ and Tea-Yub Kwon 1,3,* iD \\ 1 Institute for Biomaterials Research \& Development, Kyungpook National University, 2-188-1 Samduk-dong, \\ Jung-gu, Daegu 700-412, Korea; mhhong@knu.ac.kr \\ 2 Center for Research Facilities, Yeungnam University, 214-1 Dae-dong, Gyeongsan 712-749, Korea; \\ bkmin@ynu.ac.kr \\ 3 Department of Dental Biomaterials, School of Dentistry, Kyungpook National University, \\ 2-188-1 Samduk-dong, Jung-gu, Daegu 700-412, Korea \\ * Correspondence: tykwon@knu.ac.kr; Tel.: +82-53-660-6891
}

Academic Editor: Amir A. Zadpoor

Received: 26 June 2017; Accepted: 7 July 2017; Published: 10 July 2017

Featured Application: This article will help to find main points to be considered while applying selective laser melting technology in dentistry.

\begin{abstract}
Metal additive manufacturing (AM), especially selective laser melting (SLM), has been receiving particular attention because metallic functional structures with complicated configurations can be effectively fabricated using the technique. However, there still exist some future challenges for the fabrication of high-quality SLM products for dental applications. First, the surface quality of SLM products should be further improved by standardizing the laser process parameters or by appropriately post-treating the surface. Second, it should be guaranteed that dental SLM restorations have good dimensional accuracy and, in particular, a good marginal fit. Third, a definitive standard regarding building and scanning strategies, which affect the anisotropy, should be established to optimize the mechanical properties and fatigue resistance of SLM dental structures. Fourth, the SLM substructure's bonding and support to veneering ceramic should be further studied to facilitate the use of esthetic dental restorations. Finally, the biocompatibility of SLM dental alloys should be carefully examined and improved to minimize the potential release of toxic metal ions from the alloys. Future research of SLM should focus on solving the above challenges, as well as on fabricating dental structures with "controlled" porosity.
\end{abstract}

Keywords: additive manufacturing; anisotropy; dental alloy; selective laser melting

Additive manufacturing ( $\mathrm{AM}$ ), also known as three-dimensional (3D) printing or rapid prototyping, is the process of joining materials to make 3D objects from digital data, usually layer upon layer [1,2]. Metal AM, especially selective laser melting (SLM), has been receiving particular attention because metallic functional structures with complicated configurations in various industrial, medical, and dental sectors can now be fabricated using this technique [1-3]. However, due to the complex nature of metal AM, there still exist many challenges for the successful fabrication of high-quality metallic products with favorable microstructures and properties [3]. In particular, several challenges need to be solved in order to apply the SLM technology widely in dental applications, replacing conventional techniques such as casting [1].

It has been known that the SLM technique can produce 3D objects with minimal pre-processing and/or post-processing requirements [3]. In reality, however, the supporting structure created in the manufacturing stage must be manually removed after the final 3D product is completed $[2,4]$. 
In addition, low surface quality (such as cracking, delamination, and swelling) is one of the major drawbacks encountered in the SLM process [5]. Hong et al. [6] demonstrated that three laser process parameters (laser power, scan rate, and scan-line spacing) directly influenced the surface roughness of an SLM cobalt-chromium ( $\mathrm{Co}-\mathrm{Cr}$ ) dental alloy. Yasa et al. [5] suggested "laser re-melting," in which, after scanning a layer and melting the powder, the same slice is re-scanned before adding a new layer. Laser re-melting can also be applied to only the last layer of the SLM part to enhance the surface quality [5]. However, it is still questionable whether this technique can be applied to SLM-processed dental prostheses in general, because it may alter the dimension of the products.

SLM-fabricated fixed partial dentures have good dimensional accuracy and, in particular, a good marginal fit to minimize plaque accumulation and to reduce the chance of recurrent caries and periodontal disease (Figure 1) [1,7]. However, the dimensional accuracy of the final 3D product can be significantly jeopardized by many factors, including thermal distortion due to continuous melting and resolidification during the SLM process [6]. Kim et al. [7] reported that SLM-fabricated $\mathrm{Co}-\mathrm{Cr}$ alloy copings showed significantly larger marginal discrepancies than cast ones. In addition, Kocaağaoğlu et al. [8] showed a significantly increased marginal discrepancy after the application of veneering ceramic in the Co-Cr alloy copings produced by SLM (Figure 1). Therefore, at present, it cannot be ensured that dental SLM restorations have a good marginal fit both before and after ceramic veneering. Meanwhile, Kruth et al. [9] proposed a method of reducing the layer thickness or increasing the sloping angle during the SLM process to improve the accuracy of the final SLM framework. In addition, Yang et al. [10] suggested the use of a compound scanning method with different spot compensations to fabricate a more accurate SLM structure. Thus, the strategies for guaranteeing an accurate fit of SLM objects should be researched further.

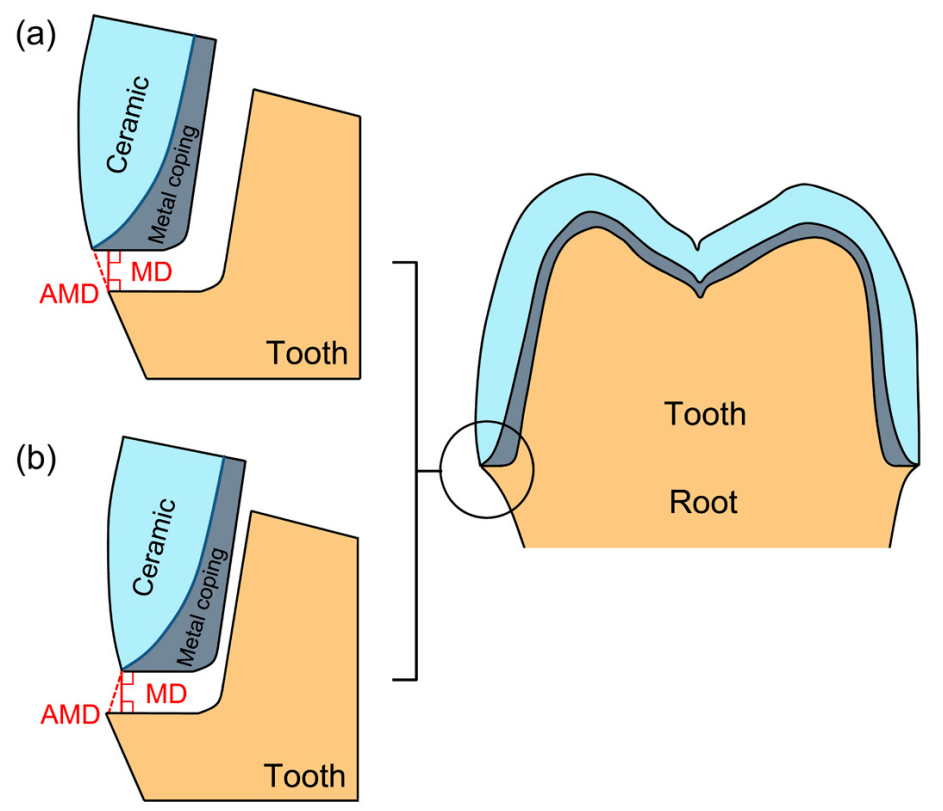

Figure 1. Schematic diagram of dental metal-ceramic crown showing (a) over-extended and (b) under-extended margins (MD: marginal discrepancy; AMD: absolute marginal discrepancy).

For dental applications, SLM-fabricated restorations should retain sufficient mechanical properties and fatigue resistance, which are directly affected by the alloy microstructures [1,11,12]. Even a little residual porosity in the SLM parts may be problematic for some applications where high strength and fatigue resistance are necessary [5]. During the SLM process, therefore, various factors such as applied process parameters and cooling cycles should be optimized carefully, depending on the alloy powder materials used (e.g., type and size distribution) $[2,6,13]$. In particular, the anisotropy of the mechanical properties is a unique characteristic of SLM builds (Figure 2) $[11,12,14-17]$. The tensile 
properties of SLM parts fabricated in different building directions depend on the metallurgical bonding between two neighbor melt tracks or layers. When an SLM structure is being built, "layer-layer" and "track-track" molten pool boundaries (MPBs) are generated by multi-layer and multi-track melt pool overlapping, respectively (Figure 2) $[16,18]$. When the structure is built vertically $\left(90^{\circ}\right)$ or horizontally $\left(0^{\circ}\right)$, the loading direction caused by an occlusal force would act on the track-track MPB surface or on the layer-layer MPB surface, respectively. When the part is built diagonally $\left(45^{\circ}\right)$, the oriented MPBs are discontinuous not only on the $\mathrm{x}-\mathrm{y}$ plane but also along the $\mathrm{z}$ axis, producing complex loads acting simultaneously along both the layer-layer and track-track MPB surfaces $[15,18]$. Thus, the differences in MPB formation can eventually influence the mechanical properties of the processed SLM structure. Kajima et al. [12] reported that SLM-produced structures exhibit significant anisotropy in their fatigue strength as well. Therefore, when a metallic dental structure is fabricated via SLM, the building direction is a primary factor to be considered during the designing process. In addition, it should be noted that the microstructural anisotropy of the SLM part is also caused by the local heat transfer condition, which can be determined by the mean of the scanning strategy [16]. At present, however, there is no definite standard or consensus on how dental SLM prostheses should be designed when considering the anisotropy issue, which mainly depends on the building and scanning strategies. Moreover, the dominant factor affecting the fatigue strength of SLM builds still remains unidentified [12]. Although the mechanical anisotropy of SLM structures have been extensively researched, most of those studies were performed using "tensile" tests $[11,15,17]$. Tests for evaluating the mechanical and fatigue behaviors of SLM products for dental applications should be accompanied with "bending" tests, which simulate a long dental bridge under occlusal load. Future research should also include studies on the effects of post-processing heat treatment of as-built SLM products for relieving the residual stress and for improving the mechanical properties and fatigue resistance [13,17]. At present, when an SLM part is applied as a dental prosthesis, it should be tested to find whether the alloy satisfies the requirements specified by ISO 22674 in terms of mechanical properties [19].

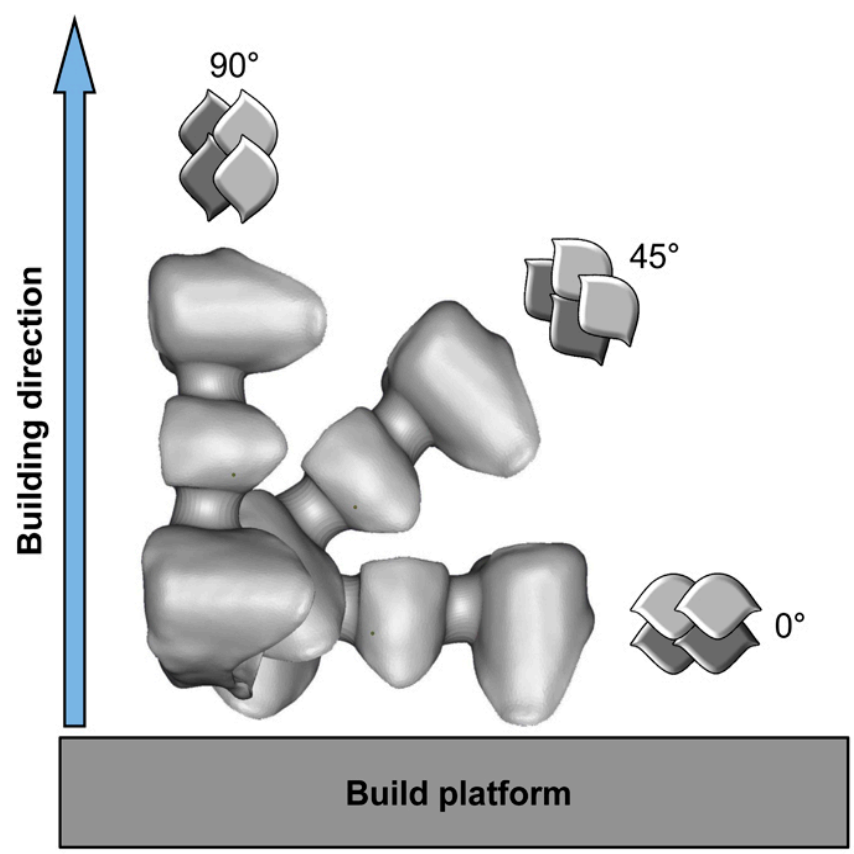

(c)

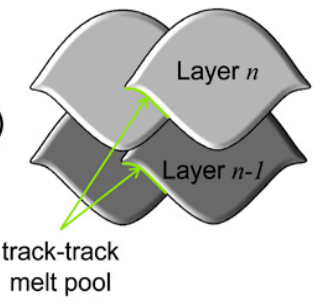

(b)

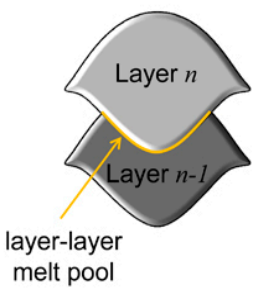

(a)

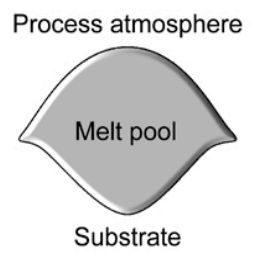

Figure 2. Processing strategies for the selective laser melting substructure of dental metal-ceramic restoration (left) and schematic representation of different types of molten pool boundaries (MPBs) (right): (a) single MPB; (b) "layer-layer" MPB; and (c) "track-track" MPB. 
It should also be noted that most dental metallic restorations produced by SLM need to be veneered with ceramic (porcelain) to match the color of the tooth for improved esthetic results [1]. The fracture of ceramic veneers is a common clinical problem that causes the premature failure of fixed partial dentures [8]. Therefore, a high bond strength between ceramic and metal in a ceramic-metal restoration is directly associated with the long-term clinical success of the restoration [1]. Ren et al. [20] and $\mathrm{Li}$ et al. [21] reported a favorable porcelain adherence of SLM-produced alloys in comparison with cast alloys. Recently, Kaleli et al. [22] demonstrated that $\mathrm{Co}-\mathrm{Cr}$ dental alloy fabricated via SLM had significantly higher bond strength than cast alloy. In metal-ceramic restorations, another frequent reason for porcelain fracture is the lack of rigidity and the distortion of the metal substructure [23]. Therefore, mechanical anisotropy should also be taken into consideration when a metal substructure for a metal-ceramic restoration is built. As stated previously, a possible change in the marginal fit of metal-ceramic restorations during the application of veneering ceramic onto an SLM substructure needs to be researched further by carefully examining the dimension and microstructure during the firing procedures [8].

At present, the SLM alloys most used for dental applications are $\mathrm{Co}-\mathrm{Cr}$ and titanium (Ti) alloys [2]. Dental alloys used in the oral environment should have a lower release of metallic ions, which may lead to adverse tissue reactions and/or hypersensitivity, to reduce risks to patient health $[1,24]$. For SLM alloys, therefore, a biocompatibility issue can be raised due to their potential release of toxic metal ions. Titanium-6 aluminum-4 vanadium (Ti-6Al-4V) alloy fabricated by SLM is suitable for implant applications owing to its favorable biocompatibility [2,25]. Xin et al. [24] reported that $\mathrm{Co}-\mathrm{Cr}$ alloy fabricated with SLM showed a lower release of toxic Co ions than cast alloy. In their study [24], the SLM consisted of a homogeneous and compact structure, unlike the cast $\mathrm{Co}-\mathrm{Cr}$ alloy that had a heterogeneous structure. Similarly, SLM Ni-Cr alloy may exhibit enhanced biocompatibility in comparison with cast $\mathrm{Ni}-\mathrm{Cr}$ alloy, possibly by improving the microstructure and, as a result, reducing the release of toxic and allergic $\mathrm{Ni}$ ions [2]. This requires in vitro and in vivo investigations in future.

As described above, SLM is a complicated metallurgical process, and many factors during the process are related to the final quality of the SLM products. SLM technology has great potential to replace existing dental manufacturing techniques such as casting and milling, for fabricating metallic structures of fixed and removable partial dentures [1]. SLM may also be suitable for printing fully dense customized Ti dental implants with high strength [26], and even for fabricating metallic porous structures with "controlled" porosity and varying designs (e.g., dental implants and scaffolds) $[2,27,28]$. In dentistry, future research of SLM should focus on overcoming the above challenges in the fabrication of "dense" metallic restorations, and on fabricating optimally "porous" structures. Moreover, the quality control of the metal powder, improvement and optimization of the processes and systems, and establishment of evaluation methods for the products should be prioritized.

Acknowledgments: This research was supported by Basic Science Research Program through the National Research Foundation of Korea (NRF) funded by the Ministry of Education (NRF-2017R1A6A3A11036498).

Author Contributions: Min-Ho Hong and Tea-Yub Kwon conceived and wrote the paper; Bong Ki Min reviewed the draft and revised it.

Conflicts of Interest: The authors declare no conflict of interest. The founding sponsors had no role in the design of the study and in the writing of the manuscript.

\section{References}

1. Koutsoukis, T.; Zinelis, S.; Eliades, G.; Al-Wazzan, K.; Rifaiy, M.A.; Al Jabbari, Y.S. Selective laser melting technique of Co-Cr dental alloys: A review of structure and properties and comparative analysis with other available techniques. J. Prosthodont. 2015, 24, 303-312. [CrossRef] [PubMed]

2. Sing, S.L.; An, J.; Yeong, W.Y.; Wiria, F.E. Laser and electron-beam powder-bed additive manufacturing of metallic implants: A review on processes, materials and designs. J. Orthop. Res. 2016, 34, 369-385. [CrossRef] [PubMed] 
3. Gu, D.; Shen, Y. Balling phenomena in direct laser sintering of stainless steel powder: Metallurgical mechanisms and control methods. Mater. Des. 2009, 30, 2903-2910. [CrossRef]

4. Barazanchi, A.; Li, K.C.; Al-Amleh, B.; Lyons, K.; Waddell, J.N. Additive technology: update on current materials and applications in dentistry. J. Prosthodont. 2017, 26, 156-163. [CrossRef] [PubMed]

5. Yasa, E.; Kruth, J.P. Microstructural investigation of Selective Laser Melting 316L stainless steel parts exposed to laser re-melting. Procedia Eng. 2011, 19, 89-95. [CrossRef]

6. Hong, M.H.; Min, B.K.; Kwon, T.Y. The Influence of process parameters on the surface roughness of a 3D-printed Co-Cr dental alloy produced via selective laser melting. Appl. Sci. 2016, 6, 401. [CrossRef]

7. Kim, E.H.; Lee, D.H.; Kwon, S.M.; Kwon, T.Y. A microcomputed tomography evaluation of the marginal fit of cobalt-chromium alloy copings fabricated by new manufacturing techniques and alloy systems. J. Prosthet. Dent. 2016, 117, 393-399. [CrossRef] [PubMed]

8. Kocaağaoğlu, H.; Kılınç, H.İ.; Albayrak, H.; Kara, M. In vitro evaluation of marginal, axial, and occlusal discrepancies in metal ceramic restorations produced with new technologies. J. Prosthet. Dent. 2016, 116, 368-374. [CrossRef] [PubMed]

9. Kruth, J.P.; Vandenbroucke, B.; Vaerenbergh, J.; Naert, I. Rapid manufacturing of dental prostheses by means of selective laser sintering/melting. In Proceedings of the 2nd International Conference on Advanced Research in Virtual and Rapid Prototyping, Leiria, Portugal, 28 September-1 October 2005.

10. Yang, Y.Q.; Lu, J.B.; Luo, Z.Y.; Wang, D. Accuracy and density optimization in directly fabricating customized orthodontic production by selective laser melting. Rapid Prototyp. J. 2012, 18, 482-489. [CrossRef]

11. Kim, H.R.; Jang, S.H.; Kim, Y.K.; Son, J.S.; Min, B.K.; Kim, K.H.; Kwon, T.Y. Microstructures and mechanical properties of $\mathrm{Co}-\mathrm{Cr}$ dental alloys fabricated by three CAD/CAM-based processing techniques. Materials 2016, 9, 596. [CrossRef]

12. Kajima, Y.; Takaichi, A.; Nakamoto, T.; Kimura, T.; Yogo, Y.; Ashida, M.; Doi, H.; Nomura, N.; Takahashi, H.; Hanawa, T.; et al. Fatigue strength of Co-Cr-Mo alloy clasps prepared by selective laser melting. J. Mech. Behav. Biomed. Mater. 2016, 59, 446-458. [CrossRef] [PubMed]

13. Abd-Elghany, K.; Bourell, D.L. Property evaluation of $304 \mathrm{~L}$ stainless steel fabricated by selective laser melting. Rapid Prototyp. J. 2012, 18, 420-428. [CrossRef]

14. Thijs, L.; Montero, S.; Maria, L.; Wauthle, R.; Xie, Q.; Kruth, J.P.; Van Humbeeck, J. Strong morphological and crystallographic texture and resulting yield strength anisotropy in selective laser melted tantalum. Acta Mater. 2013, 61, 4657-4668. [CrossRef]

15. Guan, K.; Wang, Z.; Gao, M.; Li, X.; Zeng, X. Effects of processing parameters on tensile properties of selective laser melted 304 stainless steel. Mater. Des. 2013, 50, 581-586. [CrossRef]

16. Shifeng, W.; Shuai, L.; Qingsong, W.; Yan, C.; Sheng, Z.; Yusheng, S. Effect of molten pool boundaries on the mechanical properties of selective laser melting parts. J. Mater. Res. 2014, 214, 2660-2667. [CrossRef]

17. Simonelli, M.; Tse, Y.Y.; Tuck, C. Effect of the build orientation on the mechanical properties and fracture modes of SLM Ti-6Al-4V. Mater. Sci. Eng. A 2014, 616,1-11. [CrossRef]

18. Trevisan, F.; Calignano, F.; Lorusso, M.; Pakkanen, J.; Aversa, A.; Ambrosio, E.P.; Lombardi, M.; Fino, P.; Manfredi, D. On the selective laser melting (SLM) of the AlSi10Mg alloy: Process, microstructure, and mechanical properties. Materials 2017, 10, 1-23. [CrossRef]

19. International Organization for Standardization (ISO). Dentistry-Metallic Materials for Fixed and Removable Restorations and Appliances; ISO 22674:2016; ISO: Geneva, Switzerland, 2016. Available online: https:/ /www. iso.org/standard/59620.html (accessed on 20 May 2017).

20. Ren, X.W.; Zeng, L.; Wei, Z.M.; Xin, X.Z.; Wei, B. Effects of multiple firings on metal-ceramic bond strength of Co-Cr alloy fabricated by selective laser melting. J. Prosthet. Dent. 2016, 115, 109-114. [CrossRef] [PubMed]

21. Li, J.; Chen, C.; Liao, J.; Liu, L.; Ye, X.; Lin, S.; Ye, J. Bond strengths of porcelain to cobalt-chromium alloys made by casting, milling, and selective laser melting. J. Prosthet. Dent. 2016, 118, 69-75. [CrossRef] [PubMed]

22. Kaleli, N.; Saraç, D. Comparison of porcelain bond strength of different metal frameworks prepared by using conventional and recently introduced fabrication methods. J. Prosthet. Dent. 2017, 118, 76-82. [CrossRef] [PubMed]

23. Shadid, R.M.; Sadaqah, N.R.; Abu-Naba'a, L.; Al-Omari, W.M. Porcelain fracture of metal-ceramic tooth-supported and implant-supported restorations: A review. Open J. Stomatol. 2013, 3, 411-418. [CrossRef]

24. Xin, X.Z.; Xiang, N.; Chen, J.; Wei, B. In vitro biocompatibility of Co-Cr alloy fabricated by selective laser melting or traditional casting techniques. Mater. Lett. 2012, 88, 101-103. [CrossRef] 
25. Markhoff, J.; Krogull, M.; Schulze, C.; Rotsch, C.; Hunger, S.; Bader, R. Biocompatibility and inflammatory potential of titanium alloys cultivated with human osteoblasts, fibroblasts and macrophages. Materials 2017, 10, 52. [CrossRef]

26. Chen, J.; Zhang, Z.; Chen, X.; Zhang, C.; Zhang, G.; Xu, Z. Design and manufacture of customized dental implants by using reverse engineering and selective laser melting technology. J. Prosthet. Dent. 2014, 112, 1088-1095.e1. [CrossRef] [PubMed]

27. Sing, S.L.; Wang, S.; Agarwala, S.; Wiria, F.E.; Ha, T.M.; Yeong, W.Y. Fabrication of titanium based biphasic scaffold using selective laser melting and collagen immersion. Int. J. Bioprint. 2017, 3, 65-71. [CrossRef]

28. Yan, C.; Hao, L.; Hussein, A.; Wei, Q.; Shi, Y. Microstructural and surface modifications and hydroxyapatite coating of Ti-6Al-4V triply periodic minimal surface lattices fabricated by selective laser melting. Mater. Sci. Eng. C Mater. Biol. Appl. 2017, 75, 1515-1524. [CrossRef] [PubMed]

C 2017 by the authors. Licensee MDPI, Basel, Switzerland. This article is an open access article distributed under the terms and conditions of the Creative Commons Attribution (CC BY) license (http://creativecommons.org/licenses/by/4.0/). 